\title{
Pelizaeus-Merzbacher disease, transitional form
}

INSERM

\section{Source}

INSERM. (1999). Orphanet: an online rare disease and orphan drug data base. PelizaeusMerzbacher disease, transitional form. ORPHA:280224

The transitional form of Pelizaeus-Merzbacher disease (PMD) is the intermediate form of PMD (see this term). 